\title{
JESYA
}

JURNAL EKONOMI \& EKONOMI SYARIAH

Jurnal Ekonomi \& Ekonomi Syariah Vol 3 No 1, Januari 2020

E-ISSN : 2599-3410 | P-ISSN : 2548-9836

DOI : https://doi.org/10.36778/jesya.v3i1.122

\section{Analisis Pengaruh Keterlibatan Pengguna dan Dukungan Pengawas Mengenai Kinerja Sistem Informasi Akuntasi di Bank Syariah Mandiri Yogyakarta.}

\section{Samsul Haidir}

UIN Sunan Kalijaga Yogyakarta, Indonesia. syamsulkhaidir7@gmail.com

Abstract The purpose of writing this research as an attempt to find out empirical testing and analysis rather than user involvement and supervisory support, regarding the performance of the accounting information system at the independent Islamic bank in Yogyakarta. This type of research is field research and uses quantitative methods. Where in this study using 50 respondents. The results of the study revealed that research on system development had significant differences, so that user involvement has an influence in terms of performance in the application of accounting information systems as for the support of supervisors also has a significant influence on the performance of the existing accounting information systems at independent Islamic bank Yogyakarta. Therefore, the need for support from all stackholders to continue to improve the quality of service of the information system itself to be better and compatible in the future

Keywords User Engagement, Supervisor Support, Accounting information system.

Abstrak Tujuan dalam penulisan penelitian ini sebagai salah upaya untuk mengetahui pengujian secara empirik dan melakukan analisis daripada keterlibatan pengguna serta dukungan pengawas, mengenai kinerja pada sistem informasi akuntansi di bank syariah mandiri Yogyakarta. Jenis dari penelitian yang dilakukan yakni penelitian berbasis lapangan dan memakai metode kuantitatif. Dimana dalam penelitian ini menggunakan 50 responden. Hasil dari penelitian mengungkapkan bahwa keterlibatan pengguna pada pengembangan sistem memiliki perbedaan signifikan, sehingga keterlibatan pengguna mempunyai pengaruh dalam hal kinerja di sistem pengaplikasian informasi akuntansi adapun pada dukungan pengawas juga memiliki pengaruh secara signifikan atas kinerja dari sistem informasi akuntansi yang ada di bank syariah mandiri Yogyakarta. Oleh karena itu, perlunya dukungan dari semua stackholder untuk terus meningkatkan kualitas pelayanaan dari sistem informasi itu sendiri agar lebih baik dan kompatibel kedepannya

Kata Kunci Kunci: Keterlibatan Pengguna, Dukungan Pengawas, Sistem Informasi Akuntansi

I. PENDAHULUAN 


\section{JESY}

JURNAL EKONOMI \& EKONOMI SYARIAH

Jurnal Ekonomi \& Ekonomi Syariah Vol 3 No 1, Januari 2020

E-ISSN : 2599-3410 | P-ISSN : 2548-9836

DOI : $\underline{\text { https://doi.org/10.36778/jesya.v3i1.122 }}$

Perkembangan pesat teknologi informasi di era revolusi industri 4.0 ini telah memudahkan pekerjaan manusia dalam mengakses informasi dari berbagai macam belahan dunia manapun dalam waktu yang singkat. Begitu juga dalam halnya dunia perbankan, dengan adanya teknologi diharapkan mampu menciptakan efisiensi serta efektifitas dalam perusahaan itu sendiri (Korompis, 2014). Dengan berbagai macam fitur-fitur layanan yang ditawarkan oleh perbankan syariah menggunakan teknologi kepada para pengguna (nasabah) yang diharapkan memudahkan dalam proses transaksi, seperti pelayanan e-banking, sms banking, QR pay, dan sebagainya.

Menurut Rohmas (2013) penggunan smart technology seharusnya dimanfaatkan untuk melakukan sebuah inovasi dan kratifitas sebaik mungkin dalam menjalankan roda binis terutama dalam dunia perbankan syariah, dalam mencari funding dan lending sebanyak mungkin dalam merubah paradigma pola pikir yang awal menggunakan konsep konvensional menuju konsep yang lebih digitalisasi. Dimana cara konvensional mengungkapkan bahwa kemampuan manusia sudah cukup menghuni dalam melakukan pekerjaan meskipun tanpa bantuan teknologi sekalipun, akan tetapi secara konsep digitalisasi menjastifikasi bahwa dengan adanya bantuan teknologi semakin memudahkan pekerjaan yang dilakukan secara internal maupun eksternal oleh manusia itu sendiri (Burn \& Ash, 2000).

Menurut Jogiyanto (1992) dan Krismaji (2002) item informasi akuntansi yang baik memudahkan semua stackholder dalam mengetahui akan laporan akuntasi dari perbankan syariah itu sendiri, baik nantinya digunakan oleh pengguna dari sistem informasi akuntasi. Dengan adanya suatu sistem informasi yang baik memudahkan para mitra maupun pengguna untuk bertransaksi, baik dalam hal transfer, e-banking, penarikan tunai, maupun sebagainya. Sehingga wawasan pengetahuan seorang karyawan mengenai sistem informasi menjadi faktor penting dalam meningkatkan kualitas dari sistem informasi perusahaan atau perbankan itu sendiri (Thong, 1999 \& Sedera dkk., 2010).

Dengan adanya konstruksi sistem informasi akuntansi yang kuat diharapkan akan meningkatkan kualitas pelaporan dari lembaga perbankan itu sendiri (Soudani, 2002). Sedangkan pada konsep yang kompatibel diharapkan menjadi jalan penghubung bagi para invstor di lembaga keuangan syariah dan akses informasi bagi masyarakat umum.

Sebagai mana penelitian terdahulu yang dilaksanakan oleh Soegiharto (2001), Unerman dan O’Dwyer (2006) membahas faktor-faktor apa saja yang mempengaruhi dari kinerja didalam sistem informasi akuntasi antara lain: program pendidikan dan pelatihan, keterlibatan langsung pengguna pada perluasan jaringan informasi, melalui devisi yang ada serta adanya dewan pengarah sistem informasi. Kemudian dipertegas oleh penelitian yang dilakukan Napitupulu (2015) dia mengatakan pengetahuan, keterampilan, dan kecerdikan staf individu yang terlibat tentu sangatlah penting, karena orang yang memiliki kompetensi baik akan meningkatkan nilai kinerja pada sistem informasi akuntansi (Ward \& Peppard, 2002).

Penelitian ini memfokuskan kepada analisis pengaruh keterlibatan pengguna dan dukungan dari atasan mengenai kinerja sistem informasi akuntasi di bank syariah mandiri Yogyakarta. Adapun tujuan dalam penelitian ini adalah ingin menggali sejauh mana pemanfaatan kualitas sistem informasi akuntasi mempengaruhi kepuasan pengguna dan kualitas dukungan dari atasan, sehingga stackholder tersebut mampu menciptakan sinergitas 


\section{JESYA}

JURNAL EKONOMI \& EKONOMI SYARIAH

Jurnal Ekonomi \& Ekonomi Syariah Vol 3 No 1, Januari 2020

E-ISSN : 2599-3410 | P-ISSN : 2548-9836

DOI : https://doi.org/10.36778/jesya.v3i1.122

yang memiliki dampak postif. Dengan penelitian ini pula, penulis berharap kedepanya sistem informasi akuntansi akan menggunakan artificial intelligence yang lebih kompatibel dan menjadai sarana pendukung dalam kemajuan dunia perbankan dalam membuat laporan akuntasi yang lebih efisien.

\section{LANDASAN TEORI}

\subsection{Sistem Informasi Akuntansi dan Kompentensi Pengguna SIA.}

Sistem merupakan gabungan dari berbagai macam elmen-elmen yang berkaitan satu sama lainnya serta berkerjasama dalam mengapai sebuah target yang sudah ditentukan (Diana \& Setiawati, 2011). Dimana semuanya sudah terintegrasi dan terkoneksi dari berbagai macam subtansi yang terkecil sampai yang terbesar, dalam meraih target tersebut. Adapun informasi merupakan suatu mekanisme pengelolaan data yang dijadikan sebuah informasi, yang kemudian memiliki nilai dan dimanfaatkan oleh semua orang (Bordnar \& Hopwood, 2006).

Sedangkan SIA merupakan suatu proses dimana seseorang melakukan penghimpunan, penulisan, pencadangan, dan pengolahan data yang kemudian di transformasikan menjadi sebuah informasi yang berguna bagi semua stackholder dalam mengambil sebuah keputusan (Soudani, 2012). Penggunaan sistem ini diharapkan mampu meningkatkan nilai usaha bagi suatu perusahaan. Adapun manfaat dari penerapan sistem informasi akuntansi antara lain: merevitalisasi jenis produk atau jasa dari segi kualitas, mendongkrak daya saing perusahaan secara lebih kompetitif, dan memperluas jaringan dalam hal pengetahuan (Gray, 2002).

Pentingnya suatu kecakapan dalam penguasaan sistem informasi akuntasi diharapkan mampu membuka cakrawala berfikir yang lebih baik dan komperhensif, sehingga diantaranya memudahakan dalam melihat celah peluang serta resiko kedepan khusunya dalam dunia perbankan (Marshall, 2003). Tanpa dipungkiri kegagalan dalam sebuah manajemen perbankan terkadang tidak terlepas dalam pemahaman sistem informasi akuntansi dan dukungan atasan untuk selalu peka terhadap permsalahan yang dihadapi setiap saat. Dengan koneksi dan kolekltifitas yang tinggi tentunya akan memuculkan rasa kepuasan dari pengguna itu sendri.

\subsection{Keterlibatan Pengguna dan Kualitas Manajemen Sistem Informasi Akuntansi}

Terlepas dari sistem informsi akuntansi yang baik dalam perbankan, keterlibatan pengguna merupakan suatu hal yang penting sebab memiliki tanggung jawab dan kewenangan dalam pengambilan keputusan pada penggunaya (Warren dkk., 2009). Keterlibatan pengguna juga bermanfaat dan mempunyai peranan penting dalam mempengaruhi kualitas Sistem Informasi Akuntansi (SIA) ke arah yang positif serta ada kesenagan pribadi bagi pengguna (Kujala, 2003). Oleh karena itu, keikutsertaan pengguna sangat penting untuk diperhitungkan dalam pengimplementasian sistem informasi.

Manajemen yang baik akan bertanggung jawab dalam setiap standar oprasional prosedur yang ada, dalam menjamin segala bentuk kegiatan dari sistem informasi akuntansi itu sendiri. Adapun tugas manajemen itu sendiri adalah membandingkan suatu informasi kinerja dalam hal anggaran, estimasi biaya, dan landasan utama dalam mengukur sejauh mana 


\section{JESY}

JURNAL EKONOMI \& EKONOMI SYARIAH

Jurnal Ekonomi \& Ekonomi Syariah Vol 3 No 1, Januari 2020

E-ISSN : 2599-3410 | P-ISSN : 2548-9836

DOI : https://doi.org/10.36778/jesya.v3i1.122

visi dan misi dari perbankan tersebut untuk melihat hasil yang telah dicapai dan yang belum terlaksana (Alannita \& Suaryana, 2014). Kualitas manajemen sistem informasi akuntansi diharapkan mampu meningkatkan layanan, kualitas kerja, dan konektivitas antara sub layanan satu dengan yang lainnya, tanpa adanya trouble (Soudani, 2012). Sehingga memudahkan para pengguna sistem infromasi akuntansi dalam mengambil keputusan tanpa menunggu waktu lama dengan justifikasi data-data yang sudah tersedia.

\subsection{Pengaruh kultur budaya terhadap penerapan Sistem Informasi Akuntansi}

Keanekargaman kultur budaya yang dimiliki oleh setiap bangsa terkadang menjadi nilai positif dalam membuat suatu peradaban lebih maju tanpa melupakan nilai estistika yang terkandung (Maharsi, 2000). Pengetahuan, kreatifitas dan inovasi menjadi suatu hal penting dalam melakukan elaborasi antara budaya dan teknologi (Gray, 2002).

Pengimplementasian teknologi informasi akuntansi terkadang sangatlah penting bagi setiap daerah yang ada, untuk memudahkan percepatan pembagunan dari berbagai macam aspek (Wallis, 2008). Oleh karena itu, peranan manajer menjadi sangat penting dalam melihat bagaimana penerapan sitem informasi akuntansi yang dipengaruhi letak geografi tanpa hanya mementingkan niai bisnis semata oleh para pemangku kekuasaan.

\section{METODE PENELITIAN}

Jenis penlitian ini adalah kuantitatif deskriptif yaitu dimana teknik pengumpulan data dan informasi menggunakan data primer melalui penyebaran kuesioner. Melalui penelitian deskripsi diharapkan mampu menjawab permasalahan yang terjadi baik pada tingkatan internal maupun eksternal, dalam hal penggunanan sistem informasi akuntansi (Sugiyono, 2011). Responden dalam penelitian ini awalnya menggunakan 70 orang, akan tetapi kuesioner yang terisi hanya 50 kuesioner, baik kepada para nasabah maupun pengawas bank syariah mandiri Yogyakarta itu sendiri. Adapun setelah data terkumpul tahapan selanjutnya adalah menganalisis data menggunakan uji validitas, uji reabilitas, sedangkan dalam hal analisis data melakukan uji statistik memakai metode analisis multipe regression (Ghozali, 2011).

\section{HASIL DAN PEMBAHASAN}

Kemunculan Bank Mandiri Syariah menjelang akhir tahun 1999 tidak terlepas pada kejadian krisis moneter yang menerpa Indonesia di tahun 1997-1998. Yang menyebabkan krisis pada berbagai macam sektor perekonomian dan usaha. Pada waktu itu pemerintah juga menggabungkan 4 bank diantaranya: Bank Dagang Negara, Bank Bumi Daya dan Bank Exim, serta Bapindo) kedalam satu korporasi perusahaan bank baru yaitu PT. Bank Mandiri di tanggal 31 Juli tahun 1999. Selanjutnya melakukan sebuah konsolidasi untuk membuat tim pengembangan perbankan syariah, sebagai respon dengan undang-undang yang diterbitkan yaitu nomor 10 pada tahun 1998, tentang kegiatan bank umum berhak melakukan kegiatan transaksi berbasis syariah.

PT. Bank Syariah Mandiri tercantum di Akta Notaris yang dibuat oleh: Sutjipto, S.H, berdasarkan nomor 23 pada 8 september tahun 1999. Selanjutnya terjadi perombakan kegiatan dari BSB menjelma sebagai bank umum berbasis syariah berdasarkan SK Gubernur Bank Indonesia no. 1/24/ KEP.BI/1999, pada tanggal 25 Oktober tahun 1999. Kemudian dipertegas 


\section{JESYA}

JURNAL EKONOMI \& EKONOMI SYARIAH

Jurnal Ekonomi \& Ekonomi Syariah Vol 3 No 1, Januari 2020

E-ISSN : 2599-3410 | P-ISSN : 2548-9836

DOI : https://doi.org/10.36778/jesya.v3i1.122

oleh adanya SK Deputi Gubernur BI Nomor 1/1/KEP.DGS/ 1999, dimana pada waktu Bank Indonesia (BI) mensepakati memberikan nama yaitu PT. Bank Syariah Mandiri. Serta memulai kegiatan oprasional .pada 1 November tahun 1999 (www.mandirisyariah.co.id).

\section{Hasil Uji Reliabilitas dan Uji Validitas}

\section{a. Uji Reliabilitas}

Tabel 2.1 Hasil Uji Reliabilitas

\begin{tabular}{c|r|r} 
Nama Variabel & $\begin{array}{c}\text { Cronbach's } \\
\text { Alpha }\end{array}$ & N of Items \\
\hline Keterlibatan Pengguna & .787 & 6 \\
\hline Dukungan Pengawas & .805 & 6 \\
\hline
\end{tabular}

Pada tabel 2.1 menjelaskan bahwa bagaimana keterlibatan pengguna dan dukungan atasan mengenai kinerja pada sistem akuntansi di bank syariah mandiri dengan memakai cronbach's alpha pada uji reliabilitas mempunyai batasan yaitu lebih dari 0,60. Pada hasil perhitungan didapatkan cronbach's alpha > 0,6 artinya instrumen pada kuesioner tersebut valid dan reliable.

\section{b. Uji Validitas}

Tabel 2.2 Hasil Uji Validitas

Item-Total Statistics

\begin{tabular}{|l|r|r|r|r|r|}
\hline & $\begin{array}{c}\text { Scale Mean if } \\
\text { Item Deleted }\end{array}$ & $\begin{array}{c}\text { Scale } \\
\text { Variance if } \\
\text { Item Deleted }\end{array}$ & $\begin{array}{c}\text { Corrected } \\
\text { Item-Total } \\
\text { Correlation }\end{array}$ & $\begin{array}{c}\text { Squard } \\
\text { Multipe } \\
\text { Correlation }\end{array}$ & $\begin{array}{c}\text { cronbach's } \\
\text { alpha if Item } \\
\text { Deleted }\end{array}$ \\
\hline Keterlibatan Pengguna & .692 & .827 & .823 & .835 & .432 \\
\hline Dukungan Pengawas & .812 & .811 & .885 & .824 & .638 \\
\hline
\end{tabular}

Uji validitas didapatkan berdasarkan nilai dari Corrected Item- Total Correlation. Suatu kuesioner dikatakan reliable dan valid, jika Corred Item-Total Correlation > 0,30. Seperti mana hasil dari pengujian diatas diketahui besaran nilai Corrected Item-Total Correlation di variabel Keterlibatan Pengguna yaitu .823 dan variabel Dukungan Pengawas sebesar .885. Maka dapat diambil kesimpulan dari variabel tersebut, jika Corrected ItemTotal Correlation melebihi dari 0,30 pada setiap variabel-variabel tersebut maka dikatakan valid.

\section{Uji Multikolineraritas dan Uji Signifikansi Parameter Individual}

\section{a. Uji Multikolineraritas}

Tabel 2.3 Hasil Uji Multikolineraritas 
Jurnal Ekonomi \& Ekonomi Syariah Vol 3 No 1, Januari 2020

E-ISSN : 2599-3410 | P-ISSN : 2548-9836

DOI : https://doi.org/10.36778/jesya.v3i1.122

\begin{tabular}{ll|l} 
& \multicolumn{2}{c}{ Kolinieritas Statistik } \\
Model & Tolerance & VIF \\
\hline 1 (Constant) & & \\
\hline Keterlibatan Pengguna & 0.449 & 2.228 \\
\hline Dukungan Pengawas & 0.260 & 3.848 \\
\hline
\end{tabular}

Tabel 2.3 diatas menujukkan akan hasil pada perhitungan dari nilai tolerance diketahui tidak ada sama sekali variabel independen yang mempunyai nilai tolerance rendah pada rentang 10 persen, dimana dukungan pengawas 0.260 dan keterlibatan pengguna 0.449 yang artinya tidak ada hubungan yang terkait dengan variabel independen. Begitu pula sebaliknya pada perhitungan VIF memperlihatkan bahwa tidak mempunyai satupun variabel independen yang nilai VIF lewat diantara 10 persen, dimana dukungan pengawas 3.848 dan keterlibatan pengguna 2.228. Oleh sebab itu, akhirnya diketahui tidak ada suatu problem multikolinearitas pada variabel satu dengan yang lainnya.

Selanjutnya melakukan sebuah pengujian hipotesis, akan tetapi sebelum melakukan sebuah pengujian tentunya sangat penting untuk menyusun rancangan persamaan dalam model regresi berganda sebagaimana hasil pada tabel 2.4 dibawah ini, yang nantinya menjadi dasar dalam melakukan pengujian ketahap berikutnya.

Perumpaman tahapan (a)

$$
\mathrm{Y}=\mathrm{b}+\mathrm{c}_{1} \mathrm{x}_{1}+\mathrm{c}_{2} \mathrm{x}_{2}+\mathrm{e}
$$

Perumpaman pada hasil perhitungan (b)

$$
\mathrm{Y}=1.082+115 \mathrm{X} 1+117 \mathrm{X} 2+\mathrm{e}
$$

\section{b. Uji Signifikansi Parameter Individual}

\begin{tabular}{|c|c|c|c|c|c|c|}
\hline \multicolumn{7}{|c|}{ Coefficients } \\
\hline \multirow{2}{*}{\multicolumn{2}{|c|}{ Model }} & \multicolumn{2}{|c|}{$\begin{array}{l}\text { Unstandardized } \\
\text { Coefficients }\end{array}$} & \multirow{2}{*}{$\begin{array}{c}\text { Standardized } \\
\text { Coefficients } \\
\text { Beta }\end{array}$} & \multirow[b]{2}{*}{$\mathrm{T}$} & \multirow[b]{2}{*}{ Sig. } \\
\hline & & B & Std. Error & & & \\
\hline \multirow[t]{3}{*}{1} & (Constant) & 1.082 & .936 & & 1.157 & 000 \\
\hline & Keterlibatan Pengguna & .115 & .076 & .292 & 1.516 & 001 \\
\hline & Dukungan Pengawas & .117 & .089 & .333 & 1.317 & 001 \\
\hline
\end{tabular}

Tabel 2.4 Hasil Uji Signifikansi Parameter Individual

Tahapan selanjutnya adalah melakukan pembuktian dari hipotesis yang sudah ada, sebagaimana tabel 2.4 diatas memperlihatkan hasil uji parsial yang menyatakan bahwa, hipotesis pertama mengungkapkan: Keikutsertaan para Pengguna dalam hal 


\section{JESYA}

JURNAL EKONOMI \& EKONOMI SYARIAH

Jurnal Ekonomi \& Ekonomi Syariah Vol 3 No 1, Januari 2020

E-ISSN : 2599-3410 | P-ISSN : 2548-9836

DOI : https://doi.org/10.36778/jesya.v3i1.122

pengembangan dari suatu sistem yang ada memiliki pengaruh secara kinerja SIA itu sendiri. Adapun hasil dari analisis memperlihatkan adanya tingkat singnifikan $\rho=0,001$ dari alpha $(\alpha)=0,05$. Sehingga dapat dilhat bahwa untuk hipotesis pertama ditolak dikarenakan $\rho<\alpha$, yang artinya tingkat siginifikan nilai thitung $=1.516$ pada tingkat siginifikan $\rho=0,001$ pada alpha $(\alpha)=0,05$, hal ini memperlihatkan bahwa secara signifikan memiliki pengaruh variabel keterlibatan pengguna pada suatu kinerja SIA.

Pada hipotesis kedua: Dukungan Pengawas Memiliki Pengaruh dalam hal kinerja Sistem Informasi Akuntansi. Hal ini dapat dilihat pada hasil analisis pada tingkat signifikan dari $\rho=0,001$ daripada alpha $(\alpha)=0,05$. Dimana dari hipotesis tersebut tidak dapat diterima/ditolak dikarenakan $\rho<\alpha$, artinya tingkat siginifikan nilai $t_{\text {hitung }}=1.317$ pada tingkat signifikan untuk $\rho=0,001$ atas alpha $(\alpha)=0,05$, memperlihatkan bahwa mempunyai pengaruh secara signifikan dalam hal pengembangan dukungan sistem informasi akuntansi yang ada. Sebagaimana penelitian menurut Almilia dan Briliantien (2007) mengungkapkan bahwa semakin besar suatu dukungan yang dilakukan oleh seorang manajer puncak tentu akan meningkatkan kualitas dan kuantitas dari kinerja sistem informasi akuntasi itu sendiri.

Selanjutnya yaitu untuk mengetahui formalisasi pembuktian pada setiap variabel independen, keterlibatan pengguna dan dukungan pengawas, yang kemudian dimasukan kedalam model regresi dimana nantinya memiliki pengaruh secara simultan dalam hal variabel dependen untuk kinerja pada SIA itu sendiri, sehingga dapat dilihat pada tabel dibawah ini.

Tabel 2.5 Nilai F

\begin{tabular}{|r|r|}
\hline $\mathrm{F}$ & Sig. \\
\hline 31.599 & 0,000 \\
\hline
\end{tabular}

Berdasarkan hasil tabel 2.5 diatas menujukkan bahwa nilai untuk F yaitu 31, 599 adapun untuk nilai pada propabilitas $(\mathrm{P})$ yaitu 0,000 sedangkan di alpha $(\alpha)=0,05$. Hal tersebut membuktikan bahwa pada variabel independen bahwasanya keterlibatan pengguna serta dukungan pengawas secara bersama dapat mempengaruhi suatu variabel dependen dalam hal kinerja sistem informasi akuntansi pada bank syariah mandiri Yogyakarta.

Tabel 2.6 Hasil pada Kultivasi Data Uji Statistik 


\section{JESYA}

JURNAL EKONOMI \& EKONOMI SYARIAH

Jurnal Ekonomi \& Ekonomi Syariah Vol 3 No 1, Januari 2020

E-ISSN : 2599-3410 | P-ISSN : 2548-9836

DOI : $\underline{\text { https://doi.org/10.36778/jesya.v3i1.122 }}$

\begin{tabular}{ll|l|l|l}
\cline { 4 - 5 } Hipotesis & \multicolumn{1}{c|}{ Uraian } & Sig & Keterangan \\
\hline $\mathrm{H}_{1}$ & $\begin{array}{l}\text { Keterlibatan Pengguna Memiliki } \\
\text { Pengaruh dalam Kinerja SIA }\end{array}$ & 1.516 & 0,001 & Tidak Valid \\
\hline $\mathrm{H}_{2}$ & $\begin{array}{l}\text { Dukungan daripada Pengawas } \\
\text { Memiliki Pengaruh dalam Kinerja }\end{array}$ & 1.317 & 0,001 & Tidak Valid \\
& SIA & & & \\
\hline
\end{tabular}

Dari keterangan tabel 2.6 diatas disimpulkan bahwa $\mathrm{H}_{1}$ dan $\mathrm{H}_{2}$ tidak valid dikarenakan dalam penelitian tidak mampu membuktikan pengaruh secara signifikan diantara keterlibatan pengguna serta dukungan dari pengawas dalam peningkatan kualitas kinerja pada SIA itu sendiri di bank syariah mandiri Yogyakarta. Oleh karena itu, perlu ditingkatkan kembali dalam semua lini aspek pengguna SIA dalam menunjang kualitas kinerja agar lebih positif atau lebih baik lagi kedepannya.

\section{KESIMPULAN}

Maka dari hasil penelitian yang dilakukan peneliti dilapangan dengan menyebarkan kuesioner dapat disimpulkan bahwasanya keikutsertaan pengguna pada pengembangan sistem informasi memiliki pengaruh secara signifikan pada kinerja SIA itu sendiri. Dimana para penggguna juga dilibatkan dalam hal pengembangan sistem, sehingga para pengguna merasa lebih dihargai dan puas terhadap pelayanaan sistem informasi yang ada di bank syariah mandiri Yogyakarta. Sedangkan pada dukungan pengawas juga memiliki pengaruh yang siginifikan terhadap kualitas kinerja pada sistem informasi, dikarenakan dukungan pengawas atau atasan memiliki peranan penting dalam membuat suatu kebijakan, sehingga membuat para pengguna merasa puas dalam peningkatan kualitas layanan dari SIA itu sendiri.

Penelitian ini pada dasarnya telah mengkomfirmasi bahwasanya keterlibatan pengguna dan dukungan pengawas, sama-sama memberikan kontribusi yang nyata dalam pengelolaan sistem informasi yang lebih profesional. Penelitian ini diharapkan memberikan sumabangsih baik bagi bank syariah itu sendiri dan khususnya perguruan tinggi menjadi bahan kajian yang menarik untuk dikembangkan.

\section{DAFTAR PUSTAKA}

Alannita, N.P., \& Suaryana, I.G.N.A. (2014). Pengaruh Kecanggihan Teknologi Informasi, Partisipasi Manajemen, Dan Kemampuan Teknik Pemakai Sistem Informasi Akuntansi Pada Kinerja Individu. E-Jurnal Akuntansi Universitas Udayana, 6(1), 33-45.

Almilia, L.S., \& Briliantien, I. (2007). Faktor-Faktor Yang Mempengaruhi Kinerja Sistem Informasi Akuntansi Pada Bank Umum Pemerintah di Wilayah Surabaya dan Sidoarjo, Jurnal STIE Perbanas Surabaya, 1-7. 


\section{JESYA}

JURNAL EKONOMI \& EKONOMI SYARIAH

Jurnal Ekonomi \& Ekonomi Syariah Vol 3 No 1, Januari 2020

E-ISSN : 2599-3410 | P-ISSN : 2548-9836

DOI : https://doi.org/10.36778/jesya.v3i1.122

Bodnar, G. H., \& Hopwood, W.S. (2006). Sistem Informasi Akuntansi,Cetakan I. Jakarta: Salemba Empat.

Burn,J.M., \& Ash,C. (2000). Knowledge management strategies for virtual organizations. Information resources management journal.

Diana, A., \& Setiawati, L. (2011). Sistem Informasi Akuntansi Perancangan, Proses dan Penerapan. Andi: Yogyakarta.

Ghozali, Imam. (2011). Analisis Multivarier dengan Menggunakan Program SPSS. Semarang: Badan Penerbit Universitas Diponegoro.

Gray, R. (2002). The social accounting project and accounting organizations and society: Privileging engagement, imaginings, new accountings and pragmatism over critique? Accounting Organizations \& Society, 27(7), 687-707.

Jogiyanto. (1990). Sistem Informasi Akuntansi Berbasis Komputer. Yogyakarta: BPFE.

Korompis, Claudia W.M. (2014). Dampak Teknologi Informasi dalam Pengendalian Internal untuk Mengantisipasi Kecenderungan Kecurangan Akuntansi. Jurnal Riset Akuntansi, 9(4), 27-33.

Krismaji. (2002). Sistem Informasi Akuntansi. Yogyakarta: UPP AMP YKPN.

Kujala, S., (2003), User Involvement: a review of the benefits and challenges. Journal Behaviour \& Information Technology, 22(1), 1-16.

Maharasi, S. (2000). Pengaruh Perkembangan Teknologi Informasi Terhadap Bidang Akuntansi Manajemen. Jurnal Akuntansi \& Keuangan, 2(2), 127 - 137

Marshall, R. (2003). Accounting Information System. Ninth Edition, New Jersey Pretice Hall.

Napitupulu, I.H. (2015). Impact of Organizational Culture on the Qualty of Management Accounting Information System : A Theoritical Approach. Research Journal of Finance and Accounting, 6(4), 74-83.

Rohmas, Taufiq. (2013). Sistem Informasi Manajemen. Yogyakarta: Graha Ilmu

Sedera, D., Gable, G., \& Chan, T., (2010), Knowledge Management Competence for Enterprise Success. The Journal of Strategic Information Systems, 19(4), 296-306.

Soegiharto (2001), Influence Factors Affecting The Performance of Accounting Information System. Gajah Mada International Journal of Business, 3(2), 177-202.

Soudani, S.N. (2012). The Usefulnessof an Accounting Information System for Effective Organizational Performance. International Journal of Economics and Finance, $4(5), 136-145$.

Sugiyono. 2011. Metode Penelitian Kuantitatif, Kualitatif dan R\&D. Bandung: Afabeta

Thong, J.Y.L., (1999), An Integrated Models on Information Systems Adoption in Small Business. Journal of Management Information Systems, 15(4), 187-214.

Unerman, J., \& O'Dwyer, B. (2006). Theorising accountability for NGO advocacy. Accounting, Auditing \& Accountability Journal, 19(3), 349-376.

Wallis, E. (2008). Learning agreements and socially responsible approaches to professional and human resource development in the United Kingdom. Journal of In-Service Education, 34(4), 467-482. 
Ward, J., \& Peppard, J. (2002). Strategic Planning for Information Systems. 3rd Edition. John Wiley \& Sons, Inc.

Warren, C.S., Reeve, J.M., \& Duchac, J.E. (2009). Managerial Accounting. 10th Edition. Mason-USA: South-Western Cengage Learning. 